\title{
Effect of Mathematics Practical Work Instructional Approach on Mathematics Performance and Retention of Secondary School Students
}

\author{
Unodiaku, Stanislus Sochima \\ Department of Science Education, Faculty of Education, University of Nigeria, Nsukka, Enugu State \\ unodiakustanley@gmail.com
}

\begin{abstract}
This study determined if the practical work instructional approach (PWIA) affects senior secondary school students' academic performance and retention of mathematics. The population of the study was 2709 SSS III students in the public secondary schools in the Nsukka zone of Enugu State, Nigeria. The study was guided by three research questions and three hypotheses. The hypotheses were tested at $p \leq .05$ level of significance. A multi-stage sampling technique was adopted, through which 133 subjects were randomly sampled and used for the study. Mathematics Achievement Test (MAT) instrument containing essay items and developed by the researcher was used for gathering data. The MAT was subjected to experts in Mathematics Education and Measurement and Evaluation areas for face validation and its reliability estimate was determined using the Spearman-Brown proficiency formula which yielded 0.85. The MAT was used for data collection. Data collected with the MAT were analyzed using mean and standard deviations (S.D) to answer the research questions while ANCOVA statistic was used to analyze the hypotheses $(\mathrm{p} \leq .05)$. Results of the study revealed that the practical work instructional approach is effective in teaching and learning Mathematics. Gender was found not to be a significant factor of variance in mathematics performance when PWIA is used in mathematics instruction, among other issues found in the work. It was recommended to teachers to infuse PWIA in mathematics instruction for enhanced science/technology and entrepreneurship development and sustainability in Nigeria, among other issues.
\end{abstract}

Keywords: Practical work, instructional approach, mathematics, performance and retention.

\section{Introduction}

Education is an instrument for the development of any nation in the world. Ideally, this is the belief upon which, philosophy of Nigeria education is based. The federal government of Nigeria, therefore set education to maximize the creative potentials and skills of the individual for self-fulfillment and general development of the society (FRN, 2013). This belief can be actualized through the implementation of the objectives of the Post-Basic Education and Carrier Development (PBECD) Education Program which include providing entrepreneurial, technical and vocational job-specific skills for self-reliance, and agricultural, industrial, commercial and economic development; and to provide trained manpower in the applied science, technology and commerce at sub-professional grades (FRN, 2013). More crucially, the FRN (2013) demands that the pursuance of goals of Technical and Vocational Education and Training (TVET), the curriculum for technical colleges shall include, workshop practice, entrepreneurial training, among others. Basically, implementation of PBECD objectives demands adequate training of manpower for the acquisition of much needed entrepreneurial, technical and vocational skills most essential for "providing training that enables students to acquire continuous education that makes them self-reliant, wealth creator and providers of employment" (FRN, 2013; P. 32). Furthermore, to actualize the objectives, each student offering a subject.

In Senior Secondary School level (i.e. Post-Basic Education Curriculum) should select one Trade/Entrepreneurship subject listed in TVET syllabus covering science and mathematics, Technology, Humanities and Business studies. Specifically, entrepreneurship education aimed at covering Global System Mobile phone (GSM) Maintenance and Repairs, Animal Husbandry, Fishery, Marketing, and salesmanship. These entrepreneurial education subjects are aimed at providing students with skills and competencies to become self-reliant and wealth creators. Mathematics manipulation and outstanding mathematical ability is a precise entrepreneurship education need because without mathematics there is no physics and without physics, there is no room for acquisition of GSM maintenance and repairs skills and competencies. Obviously, an entrepreneur requires knowledge and skills of basic mathematics to enable him/her to authenticate the results which will certainly make an entrepreneur succeed; and facts could be presented by using frequency distribution, bar charts, pie charts, histograms, which are all in the domain of mathematics (Odomoso and Olusesan, 2016). An entrepreneur needs to be equipped with mathematical skills, knowledge and 
competencies to function effectively in communicating business ideas, forecasting, applying trend analysis, applying statistical techniques in the analysis of data, etc. More so, mathematical ability is crucial to entrepreneurs opting for animal husbandry and fishery farming.

Because of the competencies required in the knowledge and application of mathematics in calculations of quantities, volumes, weighting/scaling, etc involved giving drugs, feeding of animals, fishes, birds, production of feeds, etc. Mathematics and statistics are also deeply involved in marketing and salesmanship which requires accurate decision-taking to succeed. Mathematics Education could positively influence the computational skill, problem-solving, analytical skill, abstract thinking skill and creative skill that encourage individual to make decisions that would benefit self and society (Odumosu; Olusesan and Adeniran, 2016). Probably because of the need for mathematics and statistics to entrepreneurs that mathematics and statistics programs such as Business Mathematics, Mathematics for Economists, Actuarial mathematics, etc have been designed to ensure competency in these areas of entrepreneurship. Obviously, to achieve success in acquiring science, technology and entrepreneurial skills demand being competent in manipulating mathematics very handsomely. Possession of Mathematics skills is a tool for achieving success in the entrepreneurial development of any nation. For instance, an entrepreneur may need to interpret results obtained from data analysis of sales. Cash flows, etc to be able to arrive at useful decisions which call for the knowledge of mathematics and so basic mathematics knowledge and skills are required to authenticate the results which will certainly make an entrepreneur succeed (Odomoso and Olusesan, 2016). Entrepreneurship education, invariably, is paramount in today's world.

Where economic recession is ravaging almost all countries of the world, and Nigeria, in particular, which is over-dependent on crude oil that its price is constantly dropping. Some important skills such as communication, decision making, innovation, analytical and creativity, which are essential ingredients for success in entrepreneurship activities can be acquired through competent manipulation of mathematics (Odomoso and Olusesan, 2016). Mathematics is a cognitive tool and indispensably an agent of development, wealth and vocational skills acquisition. Ideally, without mathematics there is no vocational skill acquisition, without vocational skill acquisition, there is no entrepreneurial skills acquisition and without entrepreneurial skill acquisition, there will be no economic self-reliance nation. It may be in due consideration of all these vital contributions and central position of mathematics to the science, technology, vocational skills and entrepreneurial development that the Nigerian government made mathematics a compulsory subject at primary and secondary school level of education in Nigeria (FRN, 2013). 21 $1^{\text {st }}$-century secondary students cannot develop or acquire vocational skills or create wealth, because students' poor performance on the subject among Nigeria primary and secondary school students is persistently reported. The Problem of poor performance in mathematics among Nigeria students have continued to be topical and attracts the attention of mathematics educators and researchers. Low attainment in mathematics among Nigerian secondary school students is a clear manifestation of this problem.

Despite numerous methods, strategies and approaches infused into teaching the subject, reports are still raging on concerning persistent upward trend in students' poor performance on the subject. Students' persistent poor performance in mathematics is evidenced in the literature (WAEC Chief Examiners' reports, 2010-2015 and NECO Chief Examiners' reports, 2011-2017; Dogo, Keyeleve and Kurumeh, 2018). Specifically, despite the importance attached to mathematics by all stakeholders in education, senior school students still perform poorly in the subject. More so, the performance of secondary school students in mathematics in the West African Senior School Certificate Examination (WASSCE) has remained consistently poor; and this phenomenon has remained a source of concern to the researcher, parents, education administrators and the Nation at large. Probably because of all these reports that Blogsport (2018) and Samanta and King (2018), all demanded that activity-based method should be used in teaching mathematics, because it makes the teaching of mathematics practical and experiential (FRN, 2013). The practical work teaching strategy is most appropriate in mathematical topics, especially geometry and measuration (Schwartz, 2014; and Unodiaku, 2018). Based on evidence and consistently poor performance of students on the subject, it appears that all methods, strategies and approaches used by the classroom teachers failed to reverse the trend. It becomes pertinent therefore to infuse practical work instructional approach in teaching and learning of mathematics as demanded by the FRN (2013). 


\section{Literature Review}

Generally, there exists a robust literature on concepts of practical work and retention as well as empirical reports on gender variability on the mathematics performance of students. Practical work is conceptualized to refer to any mathematics activity that enables the students to effectively use concrete objects, models, charts, pictures, etc, thereby making mathematics learning easy for the students to understand and internalize the basic mathematical concepts, ideas, principles and algorithms; that develops the selfconfidence and build interest in learning mathematics, and encourages social interaction and cooperation among the students as students work in groups. Mallar (2009) defined Practical work as any teaching or learning activity involving students in observing or manipulating objects or materials. Ideally, practical work may include a field trip, classroom activities and laboratory practicals. In this research work, classroom work and practical activities were the focus and are used interchangeably to mean the same thing. According to National strategies (2008), practical work is any activity that enables pupils to have directed often a hands-on experience of phenomena they are studying. This makes mathematics teaching real and understandable to the students as opposed to the abstract or theoretical presentation of facts, principles and concepts of mathematics subject matter. The researcher believes that practical work activities can strategically make clear certain fundamental concepts, ideas, principles, etc, by working with concrete materials thereby stimulating students' interests, removing mathematics phobia in them and promoting the psychomotor domain of the learners.

There is a need for a practical work teaching approach to be infused into mathematics teaching and learning insofar it is an embodiment of hands-on activities that can promote achievement and retention of mathematics learning experiences. According to Bichi (2002), retention refers to the ability to retain and consequently remember things learned, later when needed. Ausubel (1968), conceptualized retention to mean the process of maintaining the availability of a replica of the acquired new meaning or some of them. Cognitive retention in mathematics is conceptualized to refer to continued use, existence, or possession of mathematics information (Unodiaku, 2018). The researcher views retention as the ability to retain mathematics, experiences learned and recall the information later time needed. The above definitions of retention suggest that retention is a factor of academic achievement, especially in mathematics. When information is stored correctly, retrieval becomes accessible. Retention needs to be considered when measuring students' learning. The reason for students' poor performance in mathematics could be possibly linked to students' failure to retain and recall learned concepts and theories when needed at a later time. Ayuba and Timayi (2018), investigated the impact of computer-based instruction of students' performance and retention in Algebra world problems, in the Kaduna State of Nigeria.

The study investigated the retention ability of JSS students when taught algebraic world problems using CBI. The study was guided by two research questions and two null hypotheses. The population of the study comprises of junior secondary school two (JSS 2) students of the public secondary schools in Kafanchan Educational zone of Kaduna state. A simple random sampling technique was used to sample two coeducational schools. A simple random sampling technique was further used to sample two (2) intact classes from the JSS 2 arm from which 98 students were used as an effective sample for the study (50 males and 48 females). Instrument (Algebraic Word Problems Performance [AWPP]) was used for data collection. The data were analyzed using test-retest at the $\mathrm{P} \leq .05$ level of significance. The result of the study showed a significant difference in performance in favor of the CBI group. Also, the CBI group was observed to have better retention ability compared with their counterpart in the conventional group. Okwuoza, Gimbu and Durojaiye (2018), investigated the effect of Computer Assisted Instructional Package on senior secondary school students' retention of latitudes and longitudes in Abuja, Nigeria. The study investigated the effect of the CAI package on the mean retention score of senior secondary school students taught latitudes and longitudes compared to those taught the same concept using a conventional method.

The study was guided by two research questions and two null hypotheses. The sample of the study was 178 SSS 2 students ( 90 males and 88 females). The population of the study was not mentioned. The instrument used for data collection was the Mathematics Retention Test (MRT). MRT has a reliability estimate of 0.86 obtained using Pearson Product Moment correlation statistic. The content and face validity of the MRT was established by experts. The data collected were analyzed using mean and standard deviations to answer the 
research questions while t-test statistic was used in testing the hypotheses $(\mathrm{P} \leq .05)$. Findings of the study revealed that students taught latitudes and longitudes using the CAI package, retained more than those taught latitudes and longitudes using the conventional method of teaching. The effectiveness of CBI and CAI in the above studies suggests the need to conduct this study to determine the effectiveness of the practical work instructional approach on Mathematic performance and retention of secondary school students. Literature concerning gender and academic performance in Mathematics exists with varied views and findings. For instance, Unodiaku (2018) conducted a study to determine the effect of teaching geometrical and mensuration proofs with an origami-based instructional model approach among senior secondary school students in the Enugu state.

The study investigated the difference in the mean achievement of males and females students taught mathematics using the origami-based instructional model approach. The study was guided by two research questions and two null hypotheses. The population of the study consisted of 1025 SSS III students in the public secondary schools in Awgu Urban of Awgu Education zone of Enugu State. A sample of 115 SSS III students from 3 schools out of 23 SSSs that composed Awgu urban of Awgu Education zone was randomly sampled (54 males and 61 females) and used for the study. A validated instrument (MAT) with a reliability index of 0.77 established using the alpha technique was used for data collection. The data obtained with MAT was analyzed using mean, standard deviation (S.D) and analysis of covariance (ANCOVA) statistics. The hypotheses were tested at the $\mathrm{P} \leq .05$ level of significance. The result of the study showed that gender is not a significant factor of variance in mathematics performance when the teaching of mathematics is origamibased. Onyeka and Charles-Ogan (2018), conducted a study to determine the effect of the contextual application of Pythagoras' theorem in teaching geometry in senior secondary school one in River state, Nigeria. The study investigated the difference in the mean scores of male and female students when Pythagoras' theorem is applied contextually in an experimental group.

The study was guided by four research questions and three null hypotheses. Intact classes of 2010 SS I students formed the sample of the study using a simple random sampling technique. The research instrument used for the study was the Mathematics Achievement Test (MAT). The 0.78 reliability coefficient of the MAT was obtained using a test-retest method with the Pearson Product Moment Correlation Statistic. The data obtained with the MAT was analyzed using the mean, S.D, percentage and ANCOVA statistics. The result of the study revealed that male students in the experimental group performed better than their female counterparts. These studies on gender superiority in mathematics tests appear inconclusive. There is a need therefore to conduct this study on the effect of mathematics practical work instructional approach on mathematics performance and retention to see if it can bridge the gap in gender disparity in mathematics performance. These inconsistent reports on males' and females' superiority in mathematics tests appear inconclusive. The study is aimed at clarifying this notion. Considering the observed variability in cognitive ability levels of the students and the need for using an activity-based instructional approach in teaching students mathematics as demanded in the National Policy on Education (NPE) (FGN, 2013), it is pertinent therefore to seek for intervention of practical work teaching approach to determine its effectiveness in tackling the problem of poor performance and retention on mathematics among senior secondary school students.

Statement of the Problem: Despite that mathematics is the principal determinant of scientific, technological and entrepreneurial development and sustainability in any nation of the world, and all methods/strategies/approaches infused into teaching and learning of the subject, there is persistent failure to reverse the trend of the poor performance of students on mathematics, especially in the areas of geometry (National Centre for Education statistic, 2016; and Schwartz, 2014) and measuration (Edutopia, 2016; and Unodiaku, 2018). This situation is worsened by many obstacles posed by teachers' inability to use instructional materials during mathematics lesson as demanded by WAEC Chief Examiner (2012); Samanta \& King (2018); and Blogsport (2018), who all demanded that activity-based method (practical work approach) should be used in teaching mathematics, because it makes the teaching of mathematics practical and experiential (FRN, 2013). The question is, how can a practical work instructional approach be used in the teaching of mathematics among senior secondary school students? This question is the thrust of the problem in the study. 


\section{Methodology}

Quasi-experimental research of pre-test post-test non-randomized group design was used in the conduct of this study. Specifically, a non-randomized pre-test (PR - to determine the ability level of the students for positioning before treatment), post-test (PT - to determine students' performance after treatment), postpost-test (PPT - to determine the students' retention in using practical work instructional approach for solving mathematics problems) was used. The experimental group ( $\left.E_{1}\right)$ received treatment while the control group $\left(\mathrm{C}_{1}\right)$ did not receive treatment. Further treatment was given to the experimental group $\left(\mathrm{E}_{2}\right)$ to determine students who retained information provided by the use of PWIA in solving mathematics problems. The design is presented thus:

$$
\frac{\mathrm{PR}}{\mathrm{PR}}---\left(\frac{\mathrm{E}_{1}}{\mathrm{C}_{1}}\right)---\frac{\mathrm{PT}}{\mathrm{PT}}\left(\frac{\mathrm{E}_{2}}{\mathrm{C}_{2}}\right)---\frac{\mathrm{PPT}}{\mathrm{PPT}}\left(\frac{\mathrm{E}_{3}}{\mathrm{C}_{3}}\right)
$$

Where PR = pre-test (both the experimental and control groups were pretested)

PT $=$ post-test (PR reshuffled before administering to the subjects in experimental and control groups)

$\mathrm{PPT}=\mathrm{PT}=\quad$ retention test after two weeks

$\mathrm{E}_{1}=$ treatment (experimental group)

$\mathrm{C}_{1}=$ no treatment (control group)

- - - shows that the two groups (experimental and control) are not equated by random assignment.

The study was conducted in the Nsukka local government area of Engu Education Zone, Enugu State. This zone was studied because students from the zone taught by qualified mathematics teachers due to the proximity and accessibility of the schools to the University of Nigeria, Nsukka. Statistical records were obtained from the statistical unit of the Post Primary Schools Management Board (PPSMB), Nsukka Education Zonal Office (2019). 133 randomly sampled students were used for the study. The sample was composed through a multi-stage sampling technique. The first stage involved sampling 6 schools from 30 public schools. This was followed by randomly sampling one intact class from each of the 6 schools. The 6 intact classes yielded a total of 133 subjects composed of 59 males and 74 female students. Three of the 6 sampled schools were randomly assigned to experimental group A, while the remaining three schools were assigned to control group B. This yielded a total of 63 students in group A and 70 students in group B.

Purpose of the Study: The main purpose of the study was to determine empirically the effect of mathematics practical work instructional approach (PWIA) on senior secondary school students' academic performance and retention on mathematics. Specifically, the study sought to determine:

- The difference in means of achievement test scores of students taught using PWIA and those taught with a conventional approach.

- The difference in means of achievement test scores of male and female students taught mathematics using PWIA.

- The difference in means of retention test scores of students taught mathematics with PWIA and those taught with a conventional approach.

Research Questions: The study was guided by three research questions. They are posed as follows:

- What is the mean difference between the mean achievement test scores of students taught mathematics with PWIA and those taught with the conventional approach?

- What is the mean difference between the mean achievement test scores of males and females students taught mathematics with PWIA?

- What is the mean difference between the mean retention test scores of students taught mathematics with PWIA and those taught using the conventional approach? 
Hypotheses: Three formulated null hypotheses guided the study. The hypotheses were tested using $\mathrm{p} \leq .05$ level of significance.

Ho1: There is no significant mean difference between the mean achievement test scores of students taught mathematics with PWIA and those taught using the conventional approach.

$\mathbf{H o}_{2}$ : There is no significant mean difference between the mean achievement test scores of males and females students taught mathematics with PWIA.

Ho $_{3}$ : There is no significant mean difference between the mean retention test scores of students taught mathematics with PWIA and those taught with the conventional method. The researcher tested for linearity between the pre-scores and the post-scores for the studied group. Having established the existence of linearity between the groups, the researcher went ahead and carried out an analysis of covariance (ANCOVA) test. This ANCOVA test was considered necessary to ensure that cognitive ability present among the pupils was ruled out as a factor during the testing of the effect of PWIA on the participants. Mathematical Achievement Test (MAT) was the instrument used for data collection was a mathematics achievement test (MAT). The MAT was constructed by the researcher using test development principles.

The MAT contains 16 essay questions covering geometry and mensuration. Adequacy of the MAT content and the cognitive objective levels coverage of senior secondary school mathematics curriculum were guaranteed by the table of specification. After selecting the t-test items, the experts validated the instrument with regards to content and construct. The instrument was pilot-tested with a population of similar characteristics. Data obtained was analyzed using a split-halt method which yielded a reliability estimate index at .89, an indication that the MAT is reliable for use in data collection. Research questions were answered using mean and standard deviation tools; Analysis of covariance (ANCOVA) test-statistic was adopted in testing the null hypotheses at $\mathrm{p} \leq .05$ significant level. Pre-test scores were used as covariate measures. Retention was considered to have manifested when the difference in the mean performance of students exposed to PT differs from those exposed to PPT is in favor of those in PPT (gain scores).

Procedures: Students were asked to verify that: (i) angle in a minor segment of a circle is obtuse angle; (ii) angle in a major segment is an acute angle; (iii) the sum of a triangle equals 180 degrees. The students in the experimental group were trained on how to practically use cardboard papers (of different colors), folding, cutting and pasting activities to do the verification. Other materials used in the process include protractor, pair of the compass, ruler, gum, carbon paper and pencil. Mensuration and geometry are among the topics in senior secondary schools National mathematics curriculum. They were used to tailor practical work activities. Teachers who were trained by the researcher in the 6 sampled schools were co-opted as research assistants. Thereafter, the teachers administered MAT to the research subjects as a pre-test and the result was used as a model covariate measure. The teacher quality variable was controlled by the researcher by giving equal training to teachers used in both groups. The regular class teachers taught experimental group A with practical work instructional approach and lesson plan. Control B was taught also by their regular teachers in each of the sampled schools with lesson plans but, without any practical work activity. The experimental and control groups were taught the mensuration and geometry topics from senior secondary school National mathematics curriculum (FRN, 2013).

\section{Results of the Study}

The results were presented as follows:

Research Question 1: What is the mean difference between the mean achievement test scores of students taught mathematics using PWIA and those taught with the conventional approach? 
Table 1: Descriptive Statistics of Experimental $\left(E_{1}\right)$ Groups Taught with PWIA) and Control ( $\left.C_{1}\right)$ Group (those Taught with Conventional Method) in Pre-Test, Post-Test and Post-Post Tests

\begin{tabular}{|c|c|c|c|c|c|}
\hline & Studied C \& E Group & $\mathbf{N}$ & Mean & SD & Std. Error Mean \\
\hline \multirow[t]{2}{*}{ PWIA MAT Pretest } & Experimental $\quad\left(E_{1}\right)$ & 63 & 41.0251 & 17.6477 & 1.32864 \\
\hline & Control $\left(\mathrm{C}_{1}\right)$ & 70 & 42.1175 & 16.2103 & 1.10531 \\
\hline \multirow[t]{2}{*}{ PWIA MAT Posttest } & Experimental $\left(\mathrm{E}_{2}\right)$ & 63 & 62.5463 & 15.3106 & 1.2409 \\
\hline & Control $\left(\mathrm{C}_{2}\right)$ & 70 & 44.1318 & 15.6938 & 1.01034 \\
\hline \multirow[t]{2}{*}{ PWIA MAT post-post test } & Experimental $\left(\mathrm{E}_{3}\right)$ & 63 & 64.9987 & 14.2081 & 1.04872 \\
\hline & Control $\left(\mathrm{C}_{3}\right)$ & 70 & 62,7591 & 15.1638 & 0.97544 \\
\hline
\end{tabular}

From table 1 above, the pre-test mean $\left(E_{1}\right)$ group was 41.03 while that of the control $\left(C_{1}\right)$ group was 42.12 , suggesting that there is no significant difference observed between the two groups at this level. Change of smarter students in the control group showed a mean difference of 1.09. The manipulation enables the students to gain achievement increases in the post-test $\left(\mathrm{E}_{1}=62.55, \mathrm{C}_{2}=44.13\right)$ indicating that some learning was going on with the control group, but a greater mean score increase occurred with the experimental group (mean difference between $\left(E_{1}\right.$ and $E_{2}=21.52$ ). The post-post-test was to observe how much the students retained information with regards to the use of PWIA in mathematics learning which reported a mean score of $\mathrm{E}_{2}=65.0$; and $\mathrm{C}_{2}=62.76$ with a mean difference of 2.24 between the control and experimental groups. Ho: : There is no significant mean difference between the mean achievement test scores of students taught mathematics with PWIA and those taught with the conventional approach.

Table 2:

\begin{tabular}{|c|c|c|c|c|c|c|}
\hline $\begin{array}{l}\text { Source } \\
\text { Variation }\end{array}$ & Type III Sum of Squares & DF & Mean $^{2}$ & $\mathbf{F}_{\text {cal. }}$ & Sig. & Partial Eta $^{2}$ \\
\hline Corrected model & $27115.801^{a}$ & 2 & 13557.901 & 303.356 & .000 & .715 \\
\hline Intercept & 3031.884 & 1 & 3031.884 & 67.838 & .000 & .286 \\
\hline PWIA MAT Pretest & 26001.053 & 1 & 26001.053 & 581.770 & .000 & .702 \\
\hline Studied groups & 2103.721 & 1 & 2103.721 & 47.070 & .000 & .211 \\
\hline Error & 5810.112130 & 44.693 & & & & \\
\hline Total & 259148.000 & 133 & & & & \\
\hline Corrected Total & 3704.202 & 132 & & & & \\
\hline
\end{tabular}

a. $\mathrm{R}$ Squared $=.715$ (Adjusted R squared $=.712$ )

Table 2 tested the hypothesis which revealed that there was no significant mean difference between the mean of control and experimental groups as a way to show that the use of PWIA impacted upon the students' achievement on the mathematics MAT test. Analysis of covariance (ANCOVA) revealed $F(1,130)=47.070, p \leq$ $.05, \mathrm{n}^{2}=.21$. This shows that there was a significant mean difference between the mean achievement test scores of the experimental group and the control group in favor of the experimental group. It could be deducted from the table that the significant mean difference in the achievement of students in $\mathrm{E}_{2}$ and $\mathrm{C}_{2}$ was accounted for by the PWIA used, since the mean score of the pre-test was not significantly different between the groups, but the post-test showed a significant difference.

Research Question 2: What is the mean difference between the mean achievement test scores of males and females students taught mathematics with PWIA?

Table 3: Gender Group Statistics of Participants' PWIA Performance

\begin{tabular}{llllll}
\hline & Gender & $\mathbf{N}$ & $\overline{\boldsymbol{x}}$ & S.D & S.D. Error of Mean \\
\hline \multirow{2}{*}{ PWIA MAT Pre-test } & Male & 59 & 55.0144 & 8.84405 & 0.23124 \\
& Female & 74 & 51.5833 & 16.7333 & 1.00211 \\
\multirow{2}{*}{ PWIA MAT Posttest } & Male & 59 & 59.4314 & 10.00531 & 0.38648 \\
\multirow{2}{*}{ PWIA MAT post-post test } & Female & 74 & 56.1550 & 15.35128 & 0.84264 \\
& Male & 59 & 64.0074 & 11.000201 & 0.51103 \\
& Female & 74 & 59.9122 & 15.61052 & 0.85705 \\
\hline
\end{tabular}


Table 3 above showed that mathematics achievement of males students taught using PWIA differs significantly different from the achievement of females taught mathematics using a conventional approach. More so, the study showed that male students consistently outperformed the female students in the practical work teaching approach (PWIA) experiment as shown in table 3 above. Table 3 clearly indicated that the mean achievement score and standard deviation of male participants exposed to treatment recorded 59.43 and 10.01 respectively, while those of the female counterparts were 46.16 and 15.35 as mean and S.D. scores respectively. The mean difference between males and females students was 3.27 in favor of the male students, registering lower than the mean difference in the pre-test 4.43. This result indicates that the posttest mean difference among gender categories might not have shown as a result of the PWIA. The researcher noticed that this difference was established from the onset in the pre-test mean scores as can be deduced from Table 3 above (55.0144 - 51.5833 = 3.41 in favor of males). When ANCOVA statistic was customized for these mean differences, it was discovered that the differences were as a result of differences in mathematics cognitive ability and not treatment with PWIA. Therefore, the researcher did not make further analytical interpretations with regards to gender differences.

Research Question 3: What is the mean difference between the mean retention test scores of students taught mathematics with PWIA and those taught with the conventional approach? From table 1 above, the post-test was to observe how much the students retained information with regards to the use of PWIA in mathematics which reported a mean score of $E_{3}=65.0$; and $C_{3}=62.76$ with a mean difference of 2.24 obtained between the control and experimental groups.

Table 4: Tests of Between-Subjects Effects of PWIA on the Students' Dependent Variable PWIA Mat Posttest

\begin{tabular}{lllllll}
\hline Source & Type III Sum of Squares & DF & Mean $^{2}$ & F $_{\text {cal. }}$ & Sig. & Partial Eta $^{2}$ \\
\hline Corrected model & $26113.153^{a}$ & 2 & 13056.577 & 469.526 & .000 & .815 \\
Intercept & 1003.922 & 1 & 1003.922 & 36.102 & .000 & .173 \\
PWIA MAT Posttest & 25237.321 & 1 & 25237.321 & 907.556 & .000 & .810 \\
Studied groups & 602.413 & 1 & 602.413 & 21.663 & .000 & .143 \\
Error & 3615.718 & 130 & 27.808 & & & \\
Total & 310141.000 & 133 & & & & \\
Corrected Total & 21085.218 & & & & & \\
\hline
\end{tabular}

a. R square $=815$ (Adjusted $\mathrm{R}$ square $=.183$ )

Table 4 shows the ANCOVA results of students' retention gain scores on the mathematics test. The table shows that the mean retention test scores of students exposed to experimental treatment differ significantly from those in the control group. The significant mean difference in retention of experimental and control subjects was indicated $\mathrm{F}(1,130)=21.66, \mathrm{P} \leq .05, \eta^{2}=.14$ which shows that there is a significant mean difference between the mean retention scores of the studied control and experimental groups.

\section{Discussion}

The researcher did not presume that he controlled all the extraneous variables strictly. Students in the control experimental group could have interacted after school hours and shared experiences with the research process as natural to their age bracket. The mean score of the control group in $\mathrm{C}_{1}$ at the pre-test was slightly higher than that of the experimental group in $\mathrm{E}_{1}$. At the post-test, as shown in Table 1, the $\mathrm{E}_{2}$ group gained a high mean increase. The researcher noted that at the post-post-test, the $C_{3}$ and $E_{3}$ groups slightly differed in their mean scores, recording a lower mean increase than between $\mathrm{C}_{2}$ and $\mathrm{E}_{2}$. This could be attributed to the after-school interaction of groups A and B. Research question one sought to determine the mean achievement test scores of students taught with the conventional approach. Students exposed to the experimental group gained higher mean scores more than their counterparts in the control group with a mean difference of 18.41 in the post-test. This finding suggests that the practical work instructional approach is effective in teaching and learning mathematics because it improves students' performance and retention in mathematics. This finding is in agreement with what BlogSpot (2018) and Samanta \& King (2018) who all 
demanded that activity-based method should be used in teaching mathematics because it makes the teaching of mathematics practical and experiential (FRN, 2013).

In the research question, two one sought to determine the impact of PWIA on males and females students' achievement in mathematics. It was found that males students recorded mean gain achievement scores more than their female counterparts across the three tests (pre, post and post-post). ANCOVA test statistic was computed to partial out the possible effect of existing cognitive ability differences; because of that need, the researcher concluded that the gender differences could not have resulted from manipulation of the PWIA use in instruction. This result also indicated that when students were exposed to PWIA, they shared equal achievement gain consistently during the process, from pre-test to post-post-test. This finding is in agreement with an earlier report of Onyeka and Charles-Ogan (2018) who reported that male students in the experimental group performed better than their female counterparts. However, the finding disagrees with the findings of Unodiaku (2018), who reported that male and female students shared equal strength in mathematics tests. Yet more, this finding is also supported by Jane and Janet (2016); Olasehinde and Olaltoye (2014); and Unodiaku (2013) who all reported that male and female students exposed to mathematics tests performed equally.

However, Unodiaku (2018) found that males performed better than females when exposed to an origamibased instructional model approach which is activity-based. Therefore, when the practical work teaching approach is built into mathematics instruction, all learners will benefit and aptitude for mathematics interest will develop. More so, the retention capabilities of the learners will be increased handsomely as the mean difference in retention scores between males and females students was 4.095 in favor of the male students. The researcher ignored this difference as possible error variance from the chance of cognitive ability since the difference was established from the onset in the pre-test mean scores to post-post-scores. This finding is also aligned with the earlier assertion by Ndubuisi and Ekwueme (2018); and Olosunde and Olaleye (2010) who all reported that boys performed better than girls in mathematics achievement tests. More so, it is aligned with the urgent call of FRN (2013) to infuse an activity-based approach in teaching mathematics, because it makes mathematics teaching and learning practical and experiential, and hence is most likely to induce improved learning and retention, and minimize or eliminate the gender achievement gap in mathematics and science, and more critically can give room for poverty reduction and self-reliant nation.

\section{Conclusion and Recommendations}

The present study has shown that the practical work instructional approach is capable of enhancing the mathematics performance of secondary school students. This is so insofar it has impacted on students' academic performance in mathematics learning in the research. The mean difference of 2.45 between the PT and PPT scores for group E clearly indicates that some retention also occurred during the PWIA experiment. When the model of ANCOVA computation showed a significant difference in the mean performance of males and females at the pre-test trial level, it became obvious that boys and girls did not possess equal mathematics ability which caused the researcher to stop further inquiry with regards to gender differences. Rather, the researcher focused on how each gender category improved from one trial to another during the experiment. Therefore, the practical work instructional approach is capable of eliminating unequal performance in mathematics tests between males and females learners if greater retention is given to the females learners. Obviously, the practical work instructional approach is effective in retention capability in mathematics learning. Hence, the enhanced performance of students in mathematics in schools can make Nigeria achieve the noble objectives of the desired.

Recommendations/Suggestions: Based on the findings of the study, the researcher makes the following recommendations/suggestions:

- The study indicated that the practical work instructional approach is effective in training students in the acquisition of mathematics skills necessary for entrepreneurial competency; providing equal footing for males and females students. PWIA is therefore recommended to teachers to adopt and adapt it for use in the teaching of mathematics for the enhanced achievement of the students on the subject. 
- It is suggested that the Government (local, state and federal) should, therefore, organize workshop training for mathematics teachers as well as the inclusion of practical work instructional approach in the teacher-trainee mathematics program.

- It is suggested that government should ensure that authors of lower basic mathematics textbooks include practical works, methods/strategies and materials to be used to teach mathematics particularly PWIA, as instructional methods while writing mathematics textbooks.

- It is also recommended to examination bodies endeavor to include questions on practical works in their assessment of students.

- It is suggested that Education Agencies, Mathematics Association of Nigeria (MAN), Science Teachers' Association of Nigeria (STAN), among others could provide sponsorship opportunities for mathematics teachers to be trained in PWIS use as a way to facilitate the learning of the subject for entrepreneurship development and sustainability in Nigeria.

\section{References}

Ausubel, D. P. (1968). Symbolization and Symbolic thought: Response to Truth, Child Development, 30, 997 1001.

Ayuba, I. \& Timayi, J. M. (2018). Impact of Computer Based-instruction on students' performance and retention in Algebraic word problems, Kaduna State, Nigeria. Abacus: Journal of Mathematics Association of Nigeria, 43(1), 7-13.

Bichi, S. S. (2002). Effect of problem-solving and enriched curriculum in secondary school students' achievement in evolution concept. Unpublished Ph.D. Dissertation, Faculty of Education, Hamada Bello University Zaria.

Blogspot. (2018). Activity-based Teaching method - teaching strategy' eprogressiveprt/olior.blogspott.com.acti.

Dogo, D. J., Keyeleve, J. I. \& Kurumeh, M. S. (2018). Effect of Two modes of Lesson study on senior secondary students' Achievement in Algebra in Kafanchan Education Zone of Kaduna State, Nigeria. In Abacus, Journal of Mathematics Association of Nigeria, Mathematics Education Series, 43(1), 263-271.

Edutopia. (2016). 5 reasons why origami improves students' skills. George Lucas Educational Foundation, USA.

Federal Republic of Nigeria (FRN). (2013). National Policy on Education (NPE) (5 ${ }^{\text {th }}$ Edition), Lagos: NERDC Press.

Jane, S. A. \& Janet, E. M. (2016). Gender, culture and mathematics performance (Retr. From http://www.pnas.org/content/UN/gender.

Mallar, J. (2009). What is practical work? http://www.ukessays.com/e.

National Strategies. (2008). What is practical work? http://www.ukessays.com/e.

Ndubuisi, E. E. \& Ekwueme, C. O. (2018). Comparative study of three Instructional Strategies on Students' Performance in Mathematics in Phalga, Rovers State. In abacus, Journal of Mathematics Association of Nigeria, Mathematics Education Series, 32(1), 294-306.

NECO. (2014 - 2017). Chief Examiner's Reports, Minna, Niger State

NECO Chief Examiners' Reports. (2014 - 2017). Minna: Niger State.

Odumosu, M. O., Olaleye, B. O. \& Akinniyi, F. O. (2008). Science and Mathematics Education of Women: A Tool to Political Development. A Journal of Women in College of Education, 12(1), 408-409.

Odumosu, M. O., Olusesan, E. G. \& Adeniran, O. (2016). Relevance of Mathematics Education to Entrepreneurship Skills Acquisition towards realization of vision 20:2020. International Journal of Cross-Disciplinary Subjects in Education (IJCDSE), 7(2), 2768-2773.

Okwuoza, S. O., Gimba, R. W. \& Durojaiye, D. S. (2018). Effects of Computer Assisted Instructional Package on senior secondary school students' Retention in Latitudes and Longitudes in Abuja, Nigeria. Abacus: Journal.

Olasehinde, K. J., \& Olatoye, R. A. (2014). A Comparative Study of Public and Private Senior Secondary School Students' Science Achievement in Katsina State, Nigeria. Journal of Educational and Social Research, 4(3), 203.

Onyeka, E. C. \& Charles-Ogan, G. I. (2018). Contextual Application of Pythagoras' theorem in teaching geometry in senior secondary schools one in Rivers State. Abacus: Journal of Mathematics Association of Nigeria, 43(1), 283-293. 
Samanta, C. \& King, E. M. (2018). 6 key insights into the data and information education leaders want mist http://www.bookings.edu.

Schwartz, J. E. (2014). Why do people have difficulty with geometry? Person. Alum Bacon Prentice Hall.

Unodiaku, S. S. (2013). Effect of game-based instructional model approach on the pupils' achievement in arithmetic at upper primary schools level in Igbo-Etiti LGA, Enugu State. International Journal of Education, Michael Okpara University of Agriculture, Umudike, 1(1), 121-128.

Unodiaku, S. S. (2018). Teaching geometrical measuration proofs with origami-based instructional model approach among senior secondary school students in Enugu State, Abacus, Mathematics Education Series, 43(1), 24.

WAEC Chief Examiners' Reports. (2011 - 2017). Yaba: Lagos. (2014 - 2017). 